\title{
Bioaugmentation strategy for overcoming ammonia inhibition during biomethanation of a protein-rich substrate
}

Tian, Hailin; Mancini, Enrico; Treu, Laura; Angelidaki, Irini; Fotidis, loannis

Published in:

Chemosphere

Publication date:

2019

Document Version

Peer reviewed version

Link back to DTU Orbit

Citation (APA):

Tian, H., Mancini, E., Treu, L., Angelidaki, I., \& Fotidis, I. (2019). Bioaugmentation strategy for overcoming ammonia inhibition during biomethanation of a protein-rich substrate. Chemosphere, 231, 415-422.

\section{General rights}

Copyright and moral rights for the publications made accessible in the public portal are retained by the authors and/or other copyright owners and it is a condition of accessing publications that users recognise and abide by the legal requirements associated with these rights.

- Users may download and print one copy of any publication from the public portal for the purpose of private study or research.

- You may not further distribute the material or use it for any profit-making activity or commercial gain

- You may freely distribute the URL identifying the publication in the public portal

If you believe that this document breaches copyright please contact us providing details, and we will remove access to the work immediately and investigate your claim. 


\section{Accepted Manuscript}

Bioaugmentation strategy for overcoming ammonia inhibition during biomethanation of a protein-rich substrate

Hailin Tian, Enrico Mancini, Laura Treu, Irini Angelidaki, Ioannis A. Fotidis

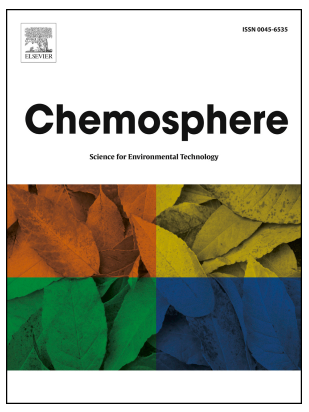

PII:

S0045-6535(19)31052-5

DOI:

https://doi.org/10.1016/j.chemosphere.2019.05.140

Reference: CHEM 23875

To appear in: $E C S N$

Received Date: 20 December 2018

Revised Date: 16 May 2019

Accepted Date: 17 May 2019

Please cite this article as: Tian, H., Mancini, E., Treu, L., Angelidaki, I., Fotidis, I.A., Bioaugmentation strategy for overcoming ammonia inhibition during biomethanation of a protein-rich substrate, Chemosphere (2019), doi: https://doi.org/10.1016/j.chemosphere.2019.05.140.

This is a PDF file of an unedited manuscript that has been accepted for publication. As a service to our customers we are providing this early version of the manuscript. The manuscript will undergo copyediting, typesetting, and review of the resulting proof before it is published in its final form. Please note that during the production process errors may be discovered which could affect the content, and all legal disclaimers that apply to the journal pertain. 


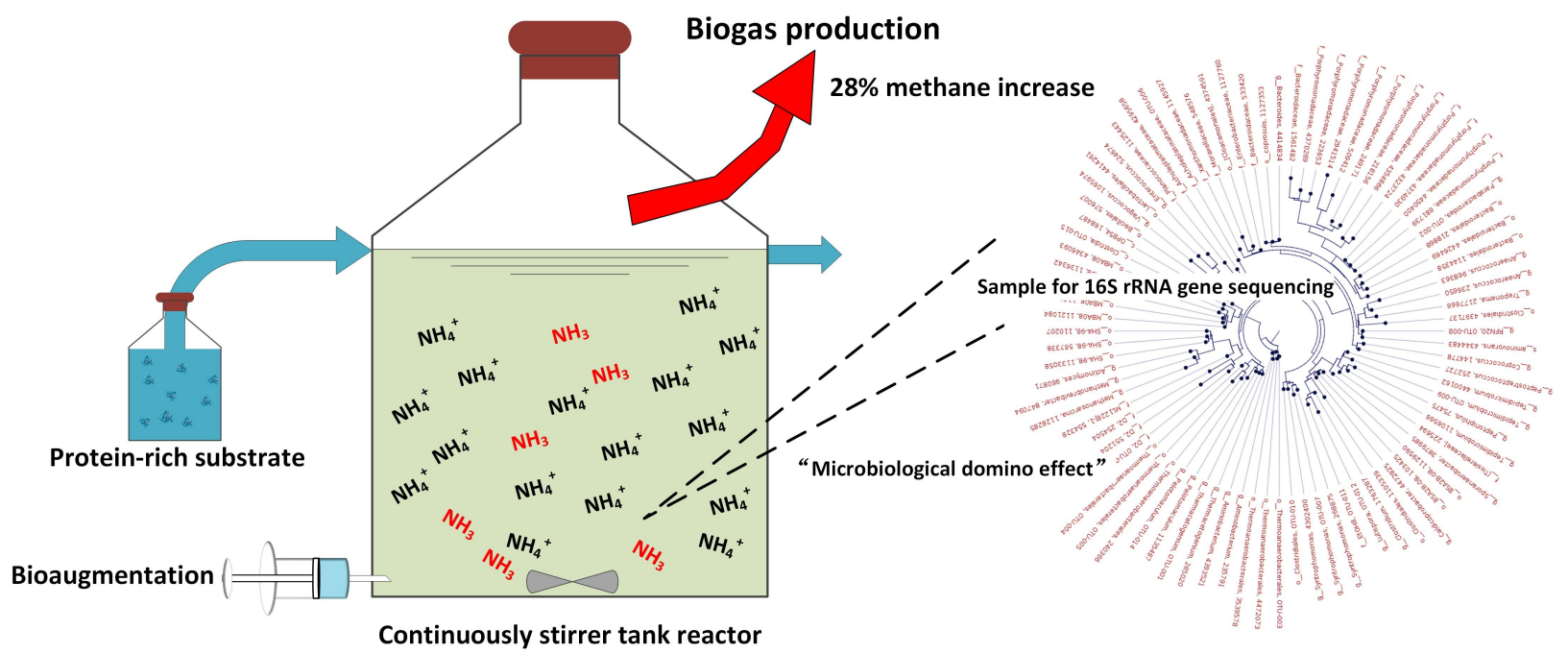




\section{Bioaugmentation strategy for overcoming ammonia inhibition}

\section{2 during biomethanation of a protein-rich substrate}

3

4 Hailin Tian, Enrico Mancini, Laura Treu, Irini Angelidaki, Ioannis A. Fotidis * 5

6 Department of Environmental Engineering, Technical University of Denmark, Bygningstorvet 7 Bygning 115, DK-2800 Kgs. Lyngby, DK

8

9 *Corresponding Author: Ioannis A. Fotidis, Department of Environmental Engineering, 10 Technical University of Denmark, Bygningstorvet Bygning 115, DK-2800 Kgs. Lyngby, 11 Denmark, Phone: (+45) 45251418; Fax: (+45) 45933850; e-mail: ioanf@env.dtu.dk 


\section{Abstract}

13 High ammonia levels inhibit anaerobic digestion (AD) process and bioaugmentation

14 with ammonia tolerant methanogenic culture is proposed to alleviate ammonia 15 inhibition. In the current study, hydrogenotrophic Methanoculleus bourgensis was

16 bioaugmented in an ammonia-inhibited continuous reactor fed mainly with microalgae

17 (a protein-rich biomass), at extreme ammonia levels (i.e. $11 \mathrm{~g} \mathrm{NH}_{4}{ }^{+}-\mathrm{N} \mathrm{L}^{-1}$ ). The results

18 showed 28\% increase in methane production immediately after bioaugmentation.

19 Moreover, volatile fatty acids decreased rapidly from more than $5 \mathrm{~g} \mathrm{~L}^{-1}$ to around $1 \mathrm{~g} \mathrm{~L}^{-}$

$20{ }^{1}$, with a fast reduction in propionate concentration. High throughput 16s rRNA gene

21 sequencing demonstrated that the bioaugmented M. bourgensis doubled its relative

22 abundance after bioaugmentation. "Microbiological domino effect", triggered by the

23 bioaugmented $M$. bourgensis establishing a newly efficient community, was proposed

24 as the working mechanism of the successful bioaugmentation. Additionally, a strong

25 aceticlastic methanogenesis was found at the end of the experiment evidenced by the

26 dominant presence of Methanosarcina soligelidi and the low abundance of syntrophic

27 acetate oxidising bacteria at the final period. Overall, for the first time, this study proved

28 the positive effect of bioaugmentation on ammonia inhibition alleviation of the

29 microalgae-dominating fed reactor, paving the way of efficient utilization of other

30 protein-rich substrates in the future.

\section{$31 \quad$ Keywords}

32 Methane; ammonia inhibition; microbial community; Methanoculleus bourgensis; 33 hydrogen partial pressure. 


\section{$34 \quad 1$ Introduction}

Biogas from anaerobic digestion (AD) is a renewable energy carrier, which plays an important role in substituting fossil fuel and contributing to the reduction of greenhouse gas emission (Chen et al., 2016). A variety of biomasses is used already as feedstock of AD process, e.g. agricultural biowaste, forestry residual and municipal sewage sludge, etc. (Chynoweth et al., 2001). Recently, protein-rich biomass, such as microalgae, which is considered as $3^{\text {rd }}$ generation biomass, is becoming an attractive feedstock due to its high methane production potential (Mahdy et al., 2017). However, high ammonia levels released from the protein degradation have been reported to cause process instability indicated by volatile fatty acids (VFA) accumulation and low methane production, and even complete process collapse (Alvarez and Lidén, 2008; Chen et al., 2008).

$\mathrm{AD}$ is a complex biological process mediated by different microorganisms, mainly bacteria and archaea. Archaea (i.e. methanogens) are more sensitive to ammonia toxicity compared to bacteria, rendering methanogenesis as the most vulnerable step of AD process (Yenigün and Demirel, 2013). Acetate is the most important precursor for methane production and is catabolized by two major pathways: 1) aceticlastic pathway mediated by aceticlastic methanogens, and 2) hydrogenotrophic pathway mediated by hydrogenotrophic methanogens coupled with syntrophic acetate oxidising bacteria (SAOB) (Zinder and Koch, 1984). Moreover, hydrogenotrophic methanogens were reported to have a higher tolerance to ammonia toxicity compared to aceticlastic methanogens (Werner et al., 2014; Dai et al., 2017; Yang et al., 2018), together with a relatively high relative abundance of SAOB at the high ammonia levels. Ammonia concentration higher than $3 \mathrm{~g} \mathrm{NH}_{4}{ }^{+}-\mathrm{N} \mathrm{L}^{-1}$ is generally accepted to cause ammonia 
58 inhibition to most of the methanogens (Nielsen and Angelidaki, 2008). Additionally,

59 free ammonia $\left(\mathrm{NH}_{3}, \mathrm{FAN}\right)$ was reported to be the most inhibitory ammonia form, which

60 can result in inhibition when the FAN concentration is above $0.15 \mathrm{~g} \mathrm{NH}_{3}-\mathrm{N} \mathrm{L}^{-1}$ (Massé 61 et al., 2014).

62 Ammonia inhibition can cause more than $30 \%$ loss of the methane potential of full-

63 scale biogas reactors digesting protein-rich substrates (Fotidis et al., 2014). In order to

64 alleviate ammonia inhibition and utilize protein-rich substrates more efficiently, many methods have been proposed in the past decades, for example, air stripping (Yuan et al., 2016), absorbing material addition (Kougias et al., 2013), dilution with tap water/

67 digested manure/ fresh manure (Nielsen and Angelidaki, 2008), etc. However, almost

68 all the proposed solutions are cost-expensive and some of them even create new

69 problems, such as increasing the total waste volume when dilution with tap water, which limits the application of these solutions (Fotidis et al., 2014). Additionally, some

71 researchers also claim that ammonia inhibition can be alleviated by indigenous microorganisms themselves because of microbial acclimation (Yenigün and Demirel, 2013; Tian et al., 2018a). However, acclimation is usually time-consuming and thus causes indirect extra economic loss for biogas plants. Recently, bioaugmentation, a process that delivers specialised microorganisms into the system to improve a specific system function, was applied successfully to recover the methane production and

77 improve reactor performance from organic overloading (Tale et al., 2015) and 78 lignocellulosic feedstocks degradation (Tsapekos et al., 2017). Thus, bioaugmentation 79 with ammonia-tolerant methanogenic culture was also proposed as a time-saving 80 solution to increase methane yield in ammonia inhibited reactors (Hao et al., 2015).

81 Successful bioaugmentation studies performed with pure hydrogenotrophic methanogen 
82 and enriched ammonia-tolerant consortia on manure-based continuously stirred tank reactor (CSTR) were reported to improve the methane production up to $36 \%$ (Fotidis et al., 2014; Fotidis et al., 2017). However, bioaugmentation on the ammonia inhibited continuous reactor fed with natural protein-rich substrates, such as $3^{\text {rd }}$ generation biomass microalgae, has never been reported. To confirm the effectiveness and develop the applicability of this technology, it is inevitable to apply bioaugmentation into reactors fed with a natural protein-rich substrate. Meanwhile, it is reported that bioaugmentation usually results in the establishment of a more efficient microbiota (Fotidis et al., 2014), thus the microbial community difference before and after

91 bioaugmentation is of great importance to elucidate the working mechanism of this 92 technology.

Therefore, the main aim of the current study was to perform bioaugmentation on an ammonia inhibited reactor fed with protein-rich substrate. The additional aim was to elucidate the bioaugmentation mechanism by deciphering the microbial community dynamics. To fulfil these aims, a mesophilic CSTR reactor fed mainly with microalgae Chlorella vulgaris, was operated under extreme ammonium levels $\left(>10 \mathrm{~g} \mathrm{NH}_{4}{ }^{+}-\mathrm{N} \mathrm{L}^{-1}\right)$, and bioaugmentation was performed on this reactor during the ammonia-induced inhibited period. Moreover, $16 \mathrm{~S}$ rRNA amplicon sequencing was applied to analyse the microbial community changes before and after bioaugmentation.

\section{$101 \quad 2 \quad$ Material and methods}

\subsection{Inoculum and feedstock}

The inoculum used to start-up the CSTR reactor was derived from a mesophilic

$104\left(37 \pm 1^{\circ} \mathrm{C}\right)$ lab-scale reactor (Tian et al., 2018a). A mixed substrate of cattle manure and 
105 microalgae $C$. vulgaris (20/80, VS/VS) was used in this study. The cattle manure, taken

106 from Hashøj Municipality (Denmark), was sieved through $1 \mathrm{~mm}$ diameter mesh, and

107 then it was stored at $-21{ }^{\circ} \mathrm{C}$ and thawed at $4{ }^{\circ} \mathrm{C}$ for $2-3 \mathrm{~d}$ before use. The protein-rich

108 substrate (protein content $49.6 \%$ of the dry mass) microalgae C. vulgaris, was

109 purchased from med24.dk in the form of capsules (detailed information is shown in

110 Table. S1, supplementary material). The capsular C. vulgaris was grinded into powder

111 using mortar and pestle before mixing it with the cattle manure. The biochemical

112 methane potential (BMP) of the microalgal biomass and the cattle manure were

113 determined according to Holliger et al. (2016) and the detailed results can be found in

114 Fig. S1 (supplementary material). The basic characteristics of the inoculum and the

115 substrates are shown in Table 1.

116 Table 1. Characteristics of the inoculum and substrates.

\begin{tabular}{llll}
\hline Parameter & Inoculum & Cattle manure & Microalgae \\
\cline { 2 - 4 } & value $\pm \mathrm{SD}^{\mathrm{a}}$ & value $\pm \mathrm{SD}^{\mathrm{a}}$ & value $\pm \mathrm{SD}^{\mathrm{a}}$ \\
\hline Total solids-TS $\left(\mathrm{g} \mathrm{kg}^{-1}\right)$ & $47.83 \pm 1.22$ & $32.90 \pm 0.02$ & $985.07 \pm 1.06$ \\
Volatile solids-VS $\left(\mathrm{g} \mathrm{kg}^{-1}\right)$ & $41.14 \pm 1.10$ & $23.00 \pm 0.04$ & $916.57 \pm 1.16$ \\
Total Ammonium nitrogen-TAN & $9.97 \pm 0.13$ & $1.10 \pm 0.12$ & $6.57 \pm 0.37$ \\
$\left(\mathrm{~g} \mathrm{NH}_{4}{ }^{+}\right.$-N kg & & \\
Total Kjeldahl nitrogen-TKN & $10.28 \pm 0.04$ & $1.49 \pm 0.01$ & $78.33 \pm 1.22$ \\
$\left(\mathrm{~g} \mathrm{~N} \mathrm{~kg}^{-1}\right)$ & & & \\
Volatile fatty acids-VFA & $2.26 \pm 0.18$ & $8.94 \pm 0.51$ & - \\
$(\mathrm{g} \mathrm{HAc} \mathrm{kg}$ & & & \\
Biochemical methane potential- & - & $332.49 \pm 7.60$ & $330.61 \pm 9.43$ \\
\hline
\end{tabular}


$\mathrm{BMP}\left(\mathrm{mL} \mathrm{CH}_{4} \mathrm{~g}^{-1} \mathrm{VS}\right)$

$117{ }^{\mathrm{a}}$ Standard deviation

\section{$118 \quad 2.2$ Bioaugmentation culture}

119 A pure strain, hydrogenotrophic Methanoculleus bourgensis $\mathrm{MS}^{\mathrm{T}}$ (DSM No. 3045), 120 purchased from DSMZ GmbH Company, was used as the bioaugmentation culture. It 121 was cultivated in the specific medium suggested by DSMZ (DSMZ, 2014) using batch 122 reactors with 238 and $80 \mathrm{~mL}$ total and working volume, respectively. The culture was 123 acclimatized to high TAN (12 $\left.\mathrm{g} \mathrm{NH}_{4}{ }^{+}-\mathrm{N} \mathrm{L} \mathrm{L}^{-1}\right)$ and FAN $\left(730 \mathrm{mg} \mathrm{NH}_{3}-\mathrm{N} \mathrm{L}^{-1}\right)$ levels by 124 adjusting the $\mathrm{pH}$ to 7.7. A mixture gas of $\mathrm{H}_{2}$ and $\mathrm{CO}_{2}(80 / 20$, v/v) was added (1 bar 125 extra) in the headspace as substrate. At the end of the exponential phase, the optical 126 density $\left(\mathrm{OD}_{600}\right)$ was determined to be 0.11 and the volatile suspended solids (VSS) were

$12720.78 \mathrm{mg} \mathrm{VSS} \mathrm{L}{ }^{-1}$. The growth curve of $M$. bourgensis used as the bioaugmentation 128 culture is presented in Fig. S2 (supplementary material).

129 Furthermore, in order to achieve a high biomass concentration for the

130 bioaugmentation, the original methanogenic culture (directly from cultivation bottles)

131 was centrifuged at $8000 \mathrm{rpm}$ for $10 \mathrm{~min}$, and then a specific amount of the supernatant 132 was removed under $\mathrm{N}_{2}$ gas headspace to up concentrate the active biomass

133 concentration by 7.5 times. Before bioaugmentation, the precipitated methanogens of

134 the bioaugmentation culture were resuspended using vortex.

\section{$135 \quad 2.3 \quad$ Experimental setup}

136 A lab-scale mesophilic $\left(37 \pm 1{ }^{\circ} \mathrm{C}\right) \mathrm{CSTR}$ reactor with 2.3 and $1.8 \mathrm{~L}$ total and

137 working volume, respectively, was used in this study. The whole system consisted of a 138 main reactor, an influent and effluent bottle, a feeding peristaltic pump, an electrical 
139 heating jacket, a water-displacement gas meter and two magnetic stirrers. The hydraulic

140 retention time (HRT) and the organic loading rate were set as $23 \mathrm{~d}$ and $2.00 \mathrm{~g} \mathrm{VS} \mathrm{L}^{-1} \mathrm{~d}^{-1}$,

141 respectively. The TAN levels in the reactor were increased from 10 to $11 \mathrm{~g} \mathrm{NH}_{4}^{+}-\mathrm{N} \mathrm{L}^{-1}$

142 using ammonium chloride $\left(\mathrm{NH}_{4} \mathrm{Cl}\right.$, CAS: 12125-02-9, Sigma-Aldrich) as extra

143 ammonia source (data not shown), and then were kept at $11 \mathrm{~g} \mathrm{NH}_{4}{ }^{+}-\mathrm{N} \mathrm{L}^{-1}$ throughout

144 the experiment. The whole experimental period was divided into three phases: P1 (d 0-

145 51); P2 (d 52-55) and P3 (d 56-139). The bioaugmentation with $20 \mathrm{~mL}$ concentrated $M$.

146 bourgensis culture was performed once per day for four consecutive days during P2.

147 Throughout the experiment, methane production, $\mathrm{pH}$, VFA and TAN levels of the

148 reactor were measured regularly, and sampling for microbial analyses was also

149 conducted.

\section{$\begin{array}{lll}150 & 2.4 & \text { Analyses }\end{array}$}

$151 \quad$ 2.4.1 Physicochemical analyses

152 TS, VS, VSS, TKN and TAN were measured based on APHA (2012). Biogas

153 composition and VFA concentration were determined by two different gas-

154 chromatographs as was described before (Tian et al., 2018b). The $\mathrm{pH}$ of samples

155 retrieved from the reactor was determined immediately by PHM99 LAB pH meter.

\section{$156 \quad 2.4 .2 \quad$ Microbial analyses}

157 Triplicate samples were taken from day 49 (before bioaugmentation, P1), day 60

158 (immediately after bioaugmentation, $\mathrm{P} 3_{\mathrm{a}}$ ) and day 134 (at the end of the experiment,

$159 \mathrm{P} 3_{\mathrm{b}}$ ), to identify the microbial dynamics. Genomic DNA extraction was done using

160 PowerSoil $\AA^{\circledR}$ DNA Isolation Kit (MO BIO laboratories Inc., Carlsbad, CA USA).

161 Universal primers 515F/806R was used for polymerase chain reaction (PCR) 
162 amplification on the V4 region of $16 \mathrm{~S}$ rRNA gene, and further amplicon sequencing

163 was performed by Illumina MiSeq platform (Ramaciotti Centre for Genomics,

164 Kensington, Australia).

165 The raw sequencing reads were deposited in Sequence Read Archive (SRA)

166 database (http://www.ncbi.nlm.nih.gov/sra) under the project of PRJNA483801. Data

167 treatment of the raw reads was performed with CLC Workbench software (V.8.0.2) with

168 microbial genomics module plug in (QIAGEN), and more details were previously

169 described (Tian et al., 2018a). Rarefaction curve (Fig. S3, Supplementary material) was

170 used to evaluate the sequencing depth. BLASTN search against $16 \mathrm{~S}$ ribosomal RNA

171 sequences (Bacteria and Archaea) database (National Center for Biotechnology

172 Information, NCBI) was used to confirm the taxonomic assignment of the most

173 interesting OTUs (relative abundance higher than $0.5 \%$ for bacteria and $0.01 \%$ for

174 archaea, Table. S2, supplementary material). Principal Component Analysis (PCA) of

175 the different samples was performed by STAMP software (Parks and Beiko, 2010),

176 while relative abundance and fold changes of the interesting OTUs at different phases

177 were depicted as heat maps through Multi experiment viewer software (MeV 4.9.0)

178 (Saeed et al., 2006).

$179 \quad 2.5$ Calculations and statistics

180 The FAN concentration was calculated according to the following equation (Tian et

181 al., 2017):

182

$183 \quad \mathrm{FAN}=\frac{\mathrm{TAN}}{1+\frac{10^{-\mathrm{pH}}}{K_{a}}} \quad$ Eq. (1) 
Where $K_{a}$ is the dissociation constant and equals to $1.29 \times 10^{-9}$ at mesophilic (37 \pm

$\left.1{ }^{\circ} \mathrm{C}\right)$ condition. was used to determine the significantly changed $(p<0.05)$ OTUs with respect to relative

190 abundance between different samples.

\section{Results and discussion}

\subsection{Reactor performance}

\subsubsection{Methane production efficiency}

194 During P1, the reactor reached an inhibited steady state (steady state was defined by

195 the variation of the methane yield less than $10 \%$ for at least ten consecutive days

196 (Hansen et al., 1998)) with methane yield of $185 \pm 12 \mathrm{~mL} \mathrm{CH}_{4} \mathrm{~g}^{-1} \mathrm{VS}$ at TAN levels of

$19711 \mathrm{~g} \mathrm{NH}_{4}^{+}-\mathrm{N} \mathrm{L}^{-1}$ (Fig. 1), which was used as the baseline to evaluate the reactor performance in the following phases. Compared to the BMP results of the substrates (Table 1), around $46 \%$ loss of the methane potential was observed during P1, which was mainly due to the high ammonia stress, thus the base line condition can be considered as an inhibited steady state.

After bioaugmentation (P3), methane yield increased immediately and reached 236

$203 \pm 9 \mathrm{~mL} \mathrm{CH}_{4} \mathrm{~g}^{-1} \mathrm{VS}$ establishing a new steady state (Fig. 1). Compared to the baseline, $20428 \%$ increase in methane yield was achieved after bioaugmentation, which 205 demonstrated a successful strategy in recovering methane production from ammonia 206 inhibited reactor. The result was similar with a previous study by Fotidis et al. (2014) 
207 reporting that a 31\% methane increase was observed after bioaugmentation in reactors

208 operated under TAN levels of only $5 \mathrm{~g} \mathrm{NH}_{4}{ }^{+}-\mathrm{N} \mathrm{L}^{-1}$. Unfortunately, due to a technical

209 problem, (i.e. the temperature of the reactor increased up to $42{ }^{\circ} \mathrm{C}$ during days 78 and

21079 due to stirrer malfunction), the methane yield of the reactor decreased rapidly, and it

211 took almost one and half HRT to recover. This phenomenon agreed with a previous

212 study (Luo et al., 2015) treating cattle manure, where the methane yield dropped close

213 to zero when the digestion temperature increased from 37 to $45^{\circ} \mathrm{C}$, and recovered after

214 one HRT. Moreover, due to the high ammonia levels in the current study, the reactor

215 became more sensitive to the temperature increase disturbance (Angelidaki and Ahring,

216 1994), which also explained the relatively long and unstable period of the reactor.

217 However, after the instability, the reactor entered a new steady state until the end of the

218 experiment with an average production of $242 \pm 7 \mathrm{~mL} \mathrm{CH}_{4} \mathrm{~g}^{-1} \mathrm{VS}$, which was $31 \%$

219 higher than the baseline. Overall, after bioaugmentation, the reactor showed a

220 significantly higher methane production efficiency $(p<0.05)$ compared to the inhibited

221 steady state, which for the first time demonstrated the positive effect of the

222 bioaugmentation strategy to alleviate ammonia inhibition of AD process fed with 223 mainly protein-rich, 3rd generation AD biomass. 


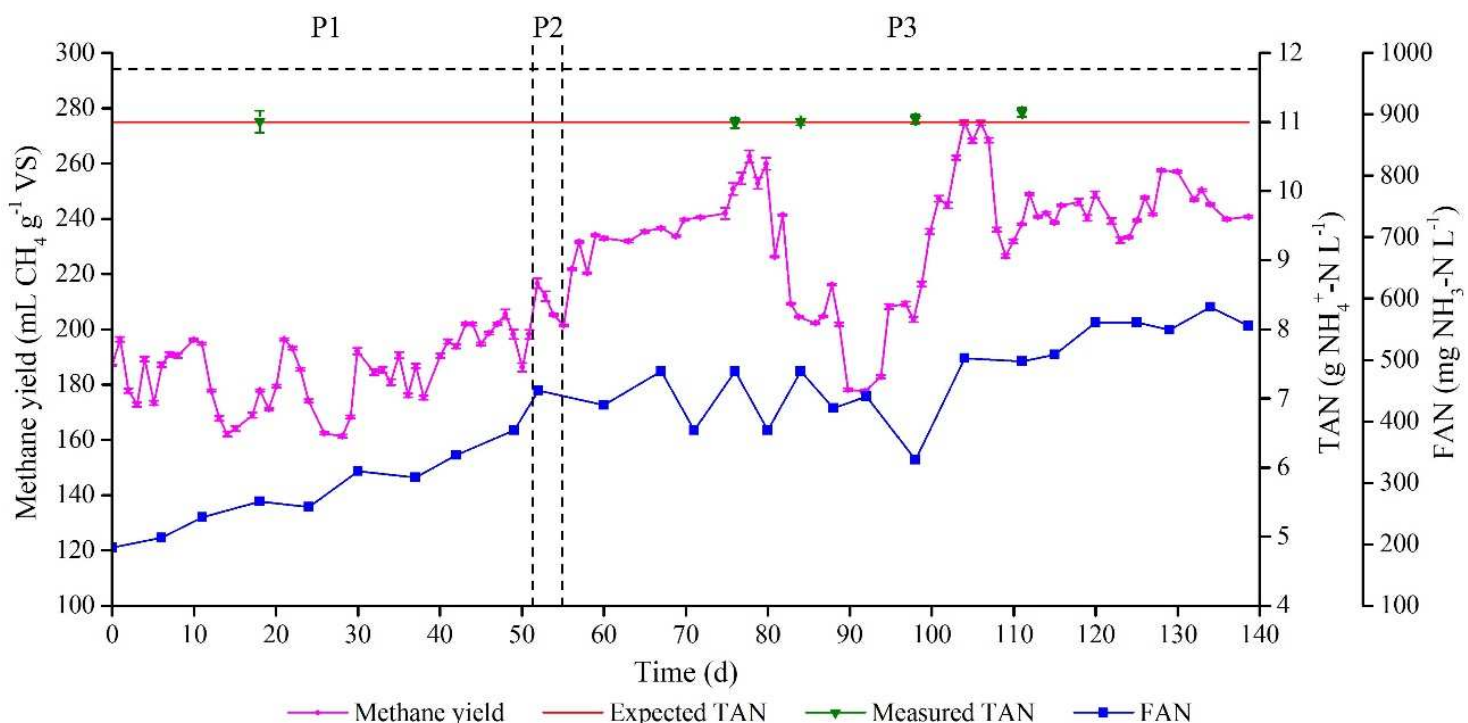

225 Fig. 1. Methane yield, TAN and FAN levels throughout the experimental period

\subsubsection{VFA and $\mathrm{pH}$ variation}

The significant decrease of total VFA concentration $(p<0.05)$ from more than $5 \mathrm{~g} \mathrm{~L}^{-}$

${ }^{1}$ to around $1 \mathrm{~g} \mathrm{~L}^{-1}$ after bioaugmentation (Fig. 2a) coincided with the increase of

methane yield discussed above. Immediately after the bioaugmentation, the total VFA

concentration started dropping, which indicated a robust bioaugmentation effect and agreed with previous studies (Fotidis et al., 2014; Fotidis et al., 2017). Moreover, synergistic inhibition of high ammonia and VFA levels was reported before (Lu et al.,

VFAs, acetate and propionate were the major intermediates accounting for at least $77 \%$

236 of the total VFA concentration during the inhibited steady state at P1, followed by isovalerate and other VFAs (Fig. 2b). Previous studies (Angelidaki and Ahring, 1994;

238 Calli et al., 2005; Nielsen and Angelidaki, 2008) also showed similar results with mainly acetate and propionate accumulation when ammonia inhibition occurred to the reactors. Moreover, propionate concentration was even higher than acetate and kept 
241 constantly higher than $2 \mathrm{~g} \mathrm{~L}^{-1}$ during the inhibitory period, which agreed with reported

242 severe inhibition when propionate concentration was higher than $0.9 \mathrm{~g} \mathrm{~L}^{-1}$ (Wang et al.,

243 2009). After bioaugmentation, propionate levels decreased rapidly from around $2.5 \mathrm{~g} \mathrm{~L}^{-1}$

244 to $0.1 \mathrm{~g} \mathrm{~L}^{-1}$, indicating a positive effect on propionate degradation resulted from

245 bioaugmentation. However, acetate levels dropped relatively slower compared to

246 propionate from $1.6 \mathrm{~g} \mathrm{~L}^{-1}$ to $0.8 \mathrm{~g} \mathrm{~L}^{-1}$. This is mainly because acetate is the intermediate

247 product of propionate degradation (Van Lier et al., 1993). Thus, it seems that propionate

248 concentration and consumption rate could be an indicator in term of ammonia inhibition

249 alleviation. Finally, pH increased slightly after bioaugmentation, which might be due to

250 the VFA consumption, but it remained within the optimal $\mathrm{pH}$ range (6.5-8.5) of $\mathrm{AD}$

251 process (Lay et al., 1998). 

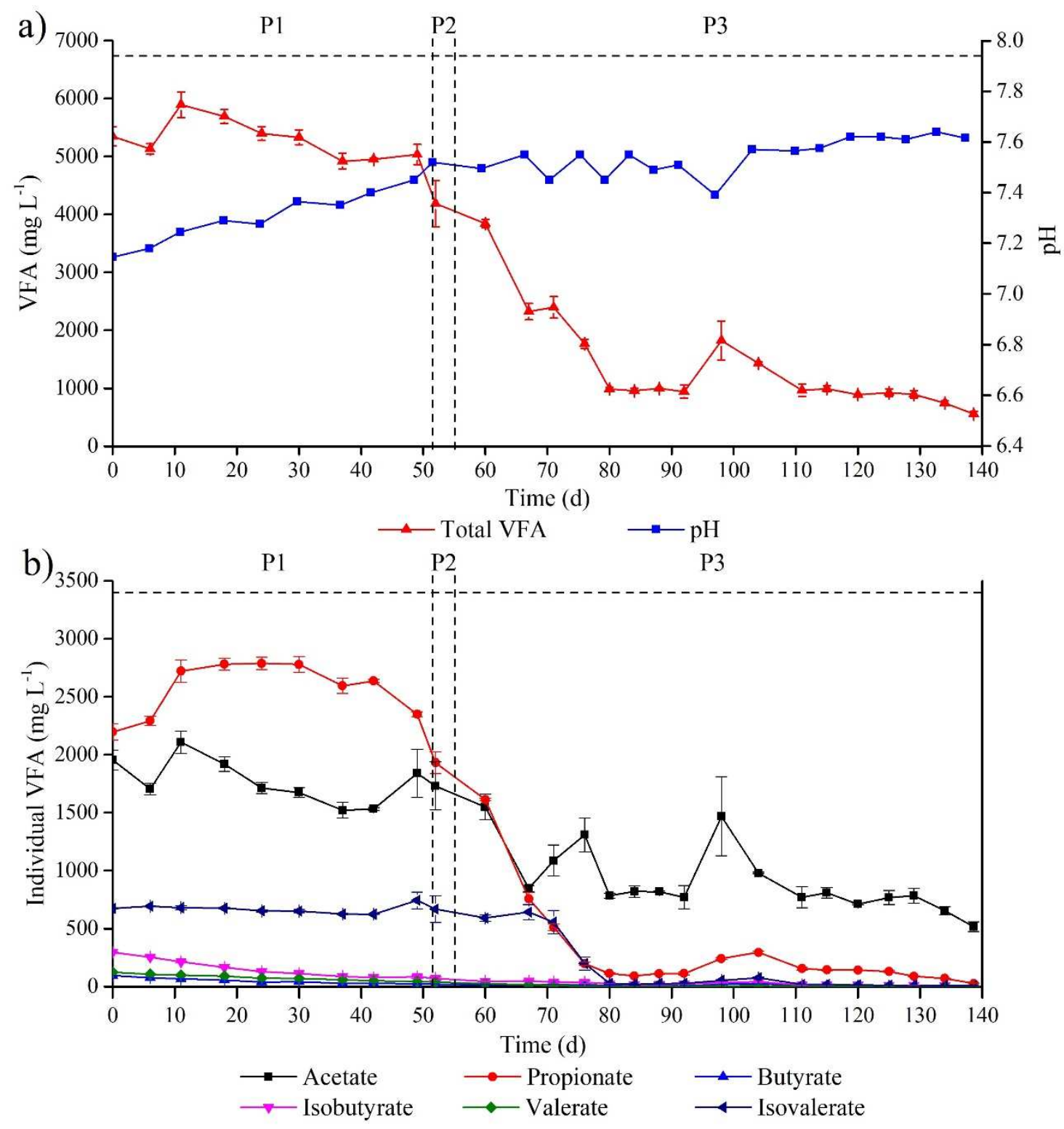

253 Fig. 2. VFA and $\mathrm{pH}$ variations throughout the experimental period: a) total VFA and $\mathrm{pH}$, b) individual VFAs.

\subsection{Microbial community composition and dynamics}

In total, around 1.8 million sequences were generated from all the triplicate samples and 1.3 million high quality sequences were assigned to OTUs. The triplicate samples of each experimental period clustered together in the PCA plot, in which principal components (PC) 1 and 2 explained $77.9 \%$ and $17.0 \%$ of the microbial composition 
260 difference, respectively. It indicated that the composition of the microbial community

261 changed significantly after bioaugmentation (Fig. 3), which agreed with previous study

262 showing big difference of the microbial community before and after bioaugmentation

263 (Fotidis et al., 2017). Moreover, it seems that temperature disturbance also strongly

264 shaped the community composition (Fig. 3) since temperature is a key factor that can

265 influence the microbial community of AD process (Luo et al., 2015; Treu et al., 2018).

266 However, even with big difference, the microbial community of all the samples still

267 consisted of mainly bacteria with relative abundance varied from 97.7 to $98.5 \%$ at

268 different phases, and archaea (methanogens) with a much smaller percentage. At

269 phylum level, only Euryachaeota was found within archaea, while Firmicutes (62.0-

270 69.4\%) and Bacteroidetes (22.7-26.6\%) composed more than 90\% of bacteria, followed

271 by Proteobacteria, Spirochaetes, Actinobacteria and WWE1, etc., which had the similar

272 overview of the microbial community compared to other studies (Gao et al., 2015;

273 Kovacs et al., 2015).

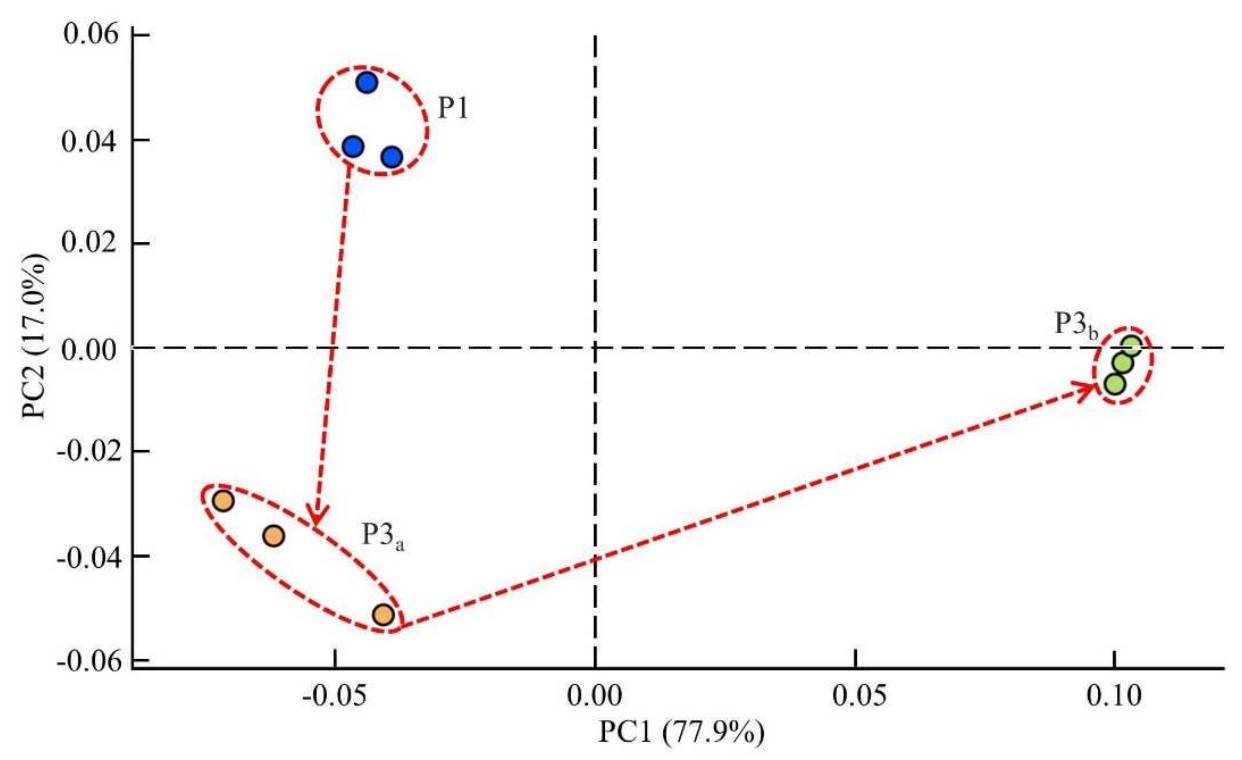


275 Fig. 3. Principal components analysis (PCA) of the triplicate samples from different periods. PC1 and PC2 stand for principal component 1 and 2, respectively. were Methanobrevibacter acididurans 1, Methanosarcina soligelidi 2 and Methanoculleus bourgensis 3 (Fig. 4a), which were identified as Methanobrevibacter acididurans, Methanosarcina soligelidi and Methanoculleus bourgensis, respectively, with the similarity value higher than 98\% through BLASTN search. Furthermore, these three OTUs were also identified to be the methanogens that changed significantly $(p<0.05)$ in relative abundance after bioaugmentation (Fig. 5a). The M. bourgensis, which was used for bioaugmentation of the reactor, was found in all the samples. However, the relative abundance with respect to the archaea community increased from $3.6 \%$ before bioaugmentation to $6.7 \%$ after bioaugmentation. Even though $M$. bourgensis was not the dominant methanogen, it seems that it was sufficient to drive the archaea community towards a more efficient methanogenesis process, which agreed with the reported "microbiological domino effect" (Fotidis et al., 2014). According to

290 this theory the bioaugmented culture, even at a relative low abundance, is sufficient to

291 drive the establishment of a new community. In fact, the bioaugmented M. bourgensis

292 in this study triggered microbial community changes (Fig. 6). The most possible 293 explanation was that the bioaugmentation of hydrogenotrophic M. bourgensis reduced 294 the hydrogen partial pressure by consuming hydrogen, which created 295 thermodynamically favourable conditions for VFAs degradation (Fig. 2), such as 296 acetate and propionate due to their sensitivity to hydrogen (Massé and Droste, 2000; 297 Hao et al., 2017). The reduced VFA levels further mitigated the synergistic inhibition of 298 ammonia and VFA, and allowed the growth of other methanogens, such as aceticlastic 
299 M. soligelidi, which was found to be dominant at high ammonia levels in previous

300 studies (Calli et al., 2005; Tian et al., 2018a). Therefore, as a result, the relative

301 abundance of $M$. soligelidi increased from $36.3 \%$ to $66.1 \%$ immediately after

302 bioaugmentation and reached $86.9 \%$ at the end of the experiment as the most dominant

303 species. However, M. acididurans, the most dominant methanogen before

304 bioaugmentation, accounted for more than half of the relative abundance of archaea. It

305 decreased in relative abundance to less than $20 \%$ and $5 \%$ immediately after

306 bioaugmentation and at the end of the experiment, respectively. Although $M$.

307 acididurans was identified as a hydrogenotrophic methanogen, its growth rate can

308 decrease more than $100 \%$ when the $\mathrm{pH}$ was increased from 7.2 to 7.5 (Savant et al.,

309 2002), which happened in the current study, where the $\mathrm{pH}$ increased up to 7.6. This $\mathrm{pH}$

310 increase can explain the decrease of M. acididurans and the poor reactor performance

311 during the inhibited steady state. 
a)

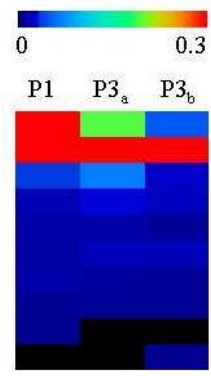

b)
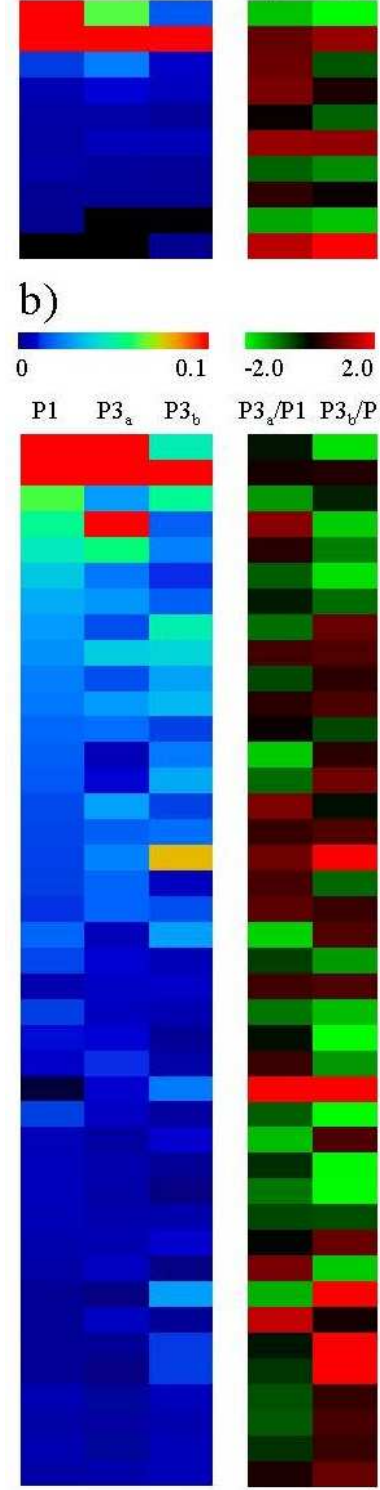

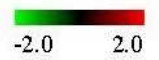

Archaea

$\mathrm{P} 3 / \mathrm{P} 1 \quad \mathrm{P} 3_{\mathrm{b}} / \mathrm{P} 1$

Methanobrevibacter acididurans

Methanosarcina soligelidi 2

Methanoculleus bourgensis 3

Methanomassiliicoccaceae sp. 4

Methanobrevibacter millerae 5

Methanoculleus palmolei 6

Methanomassiliicoccaceae sp. 7

Methanomassiliicoccus luminyensis 8

Methanobrevibacter olleyae 9

Methanomassiliicoccaceae sp. 10

\section{Bacteria}

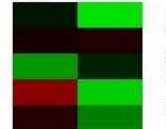

Syntrophaceticus schinkii 11

Bacillaceae sp. 12

Marinilabiliaceae sp. 13

Bacteroidales sp. 14

Thermoactinomycetaceae $\mathrm{sp} .15$

Clostridium ultunense 16

Syntrophomonadaceae sp. 17

Bacteroides coprosuis 18

Thermoanaerobacteraceae sp. 19

Catabacteriaceae sp. 20

Thermoanaerobacteraceae sp. 21

Fermentimonas caenicola 22

Synergistaceae sp. 23

Syntrophomonas sapovorans 24

Thermoanaerobacteraceae sp. 25

Thermoanaerobacteraceae sp. 26

Bacteroidaceae sp. 27

Dysgonamonadaceae sp. 28

Fermentimonas sp. 29

Spirochaetaceae sp. 30

Vagococcus humatus 31

Thermoanaerobacteraceae sp. 32

Syntrophaceticus sp. 33

Clostridiaceae sp. 34

Porphyromonadaceae sp. 35

Lysinibacillus alkalisoli 36

Vagococcus sp. 37

Synergistaceae sp. 38

Psychrobacter sp. 39

Clostridiaceae sp. 40

Thermoactinomycetaceae sp. 41

Clostridiaceae sp. 42

Aminobacterium colombiense 43

Cloacamonae sp. 44

Peptoniphilus stercorisuis 45

Catabacteriaceae sp. 46

Cryptanaerobacter sp. 47

Tepidanaerobacter acetatoxydans 48

Wohlfahrtiimonas sp. 49

Petrimonas sp. 50

Sporanaerobacter sp. 51

Shest

313 Fig. 4. Relative abundance (\%) (left part) and the corresponding folds change (right part)

314 for the interesting a) archaea and b) bacteria at different phases.

315 Within bacteria community, the first interesting and abundant OTU was

316 Syntrophaceticus schinkii 11 (Fig. 4b), that together with Syntrophaceticus sp. 33, were

317 assigned to a well-known SAOB, Syntrophaceticus schinkii (Westerholm et al., 2010).

318 Moreover, another mesophilic SAOB, Clostridium ultunense (Schnürer, 1996), was also 
319 found in this study as OTU Clostridium ultunense 16 (Fig. 4b). Overall, relative

320 abundance of SAOB was similar $(p>0.05)$ between $\mathrm{P} 1$ and $\mathrm{P} 3_{\mathrm{a}}(17.1-20.9 \%)$ but

321 decreased significantly $(p<0.05)$ down to $6.2 \%$ at the end of this experiment $\mathrm{P} 3_{\mathrm{b}}$,

322 indicating a stronger hydrogenotrophic methanogenesis at P1 and the period

323 immediately after bioaugmentation, compared to the end of the experiment. This change

324 was also in accordance with the changes between hydrogenotrophic and aceticlastic

325 methanogens discussed above. However, considering the similar levels of SAOB, but

326 worse reactor performance at $\mathrm{P} 1$ (before bioaugmentation) compared to $\mathrm{P} 3_{\mathrm{a}}$

327 (immediately after bioaugmentation), it seems that the bioaugmented M. bourgensis was

328 more efficient than $M$. acididurans on hydrogen consumption in the current

329 experimental conditions. Another interesting OTU, Bacteroidales sp. 14, which was

330 identified to be a significantly $(p<0.05)$ changed OTU and had the biggest contribution

331 to the whole community change (Fig. 5a) compared to other OTUs, was $82 \%$ similar to

332 Parafilimonas terrae, who has the ability to utilize propionic acid (Kim et al., 2014).

333 Furthermore, $P$. terrae was phylogenetically closest to Filimonas, which was reported

334 to have a positive relationship with the propionate assimilation (Albert et al., 2016).

335 Therefore, the significant increase in relative abundance of Bacteroidales sp. 14 was

336 attributed to the sharp decrease of propionate concentration after bioaugmentation (Fig.

337 2b). It is also noteworthy that Bacillaceae sp. 12, which was either the second or the

338 highest abundant OTU throughout the experimental period, cannot be allocated at

339 species levels, but belongs to uncultured SHA-98 order, which was reported to ferment

340 different organic matters at high ammonia levels (Mei et al., 2016; Müller et al., 2016).

341 Considering other five OTUs (Thermoanaerobacteraceae sp. 19,

342 Thermoanaerobacteraceae sp. 21, Synergistaceae sp. 23, Thermoanaerobacteraceae sp. 
343 26, Synergistaceae sp. 38) that belong to SHA-98, in total their relative abundance

344 increased gradually from $20.1 \%$ before bioaugmentation to $26.4 \%$ at the end, indicating

345 more efficient substrate degradation after bioaugmentation, which agreed with the

346 higher methane yield compared to the inhibited steady state (Fig. 1). Furthermore, some

347 other groups of OTUs that were suspected to contribute to the substrate utilization also

348 increased gradually after bioaugmentation, for example, three OTUs

349 (Syntrophomonadaceae sp. 17, Syntrophomonas sapovorans 24 and Lysinibacillus

350 alkalisoli 36) that related to lipid degradation and several OTUs

351 (Thermoactinomycetaceae sp. 15, Bacteroides coprosuis 18, Catabacteriaceae sp. 20,

352 Dysgonamonadaceae sp. 28, etc.) that were involved with carbohydrate/ cellulose

353 fermentation. 
a)

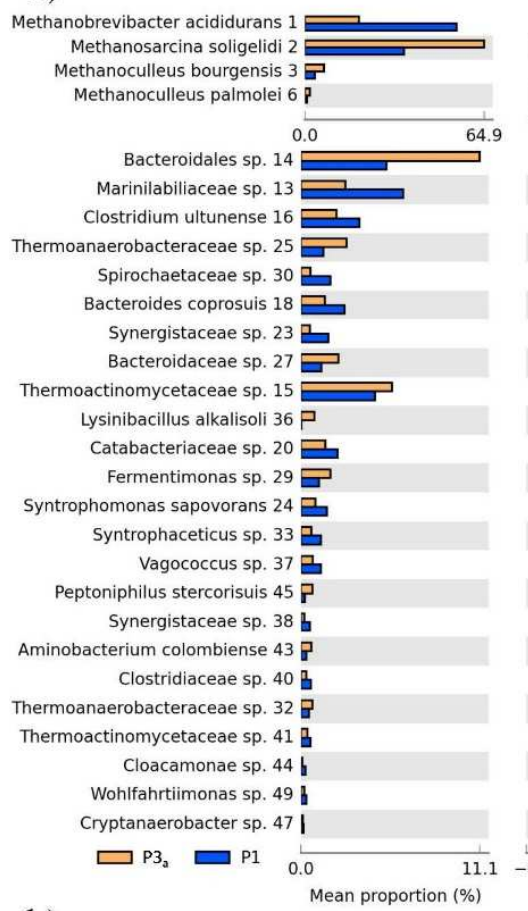

b)
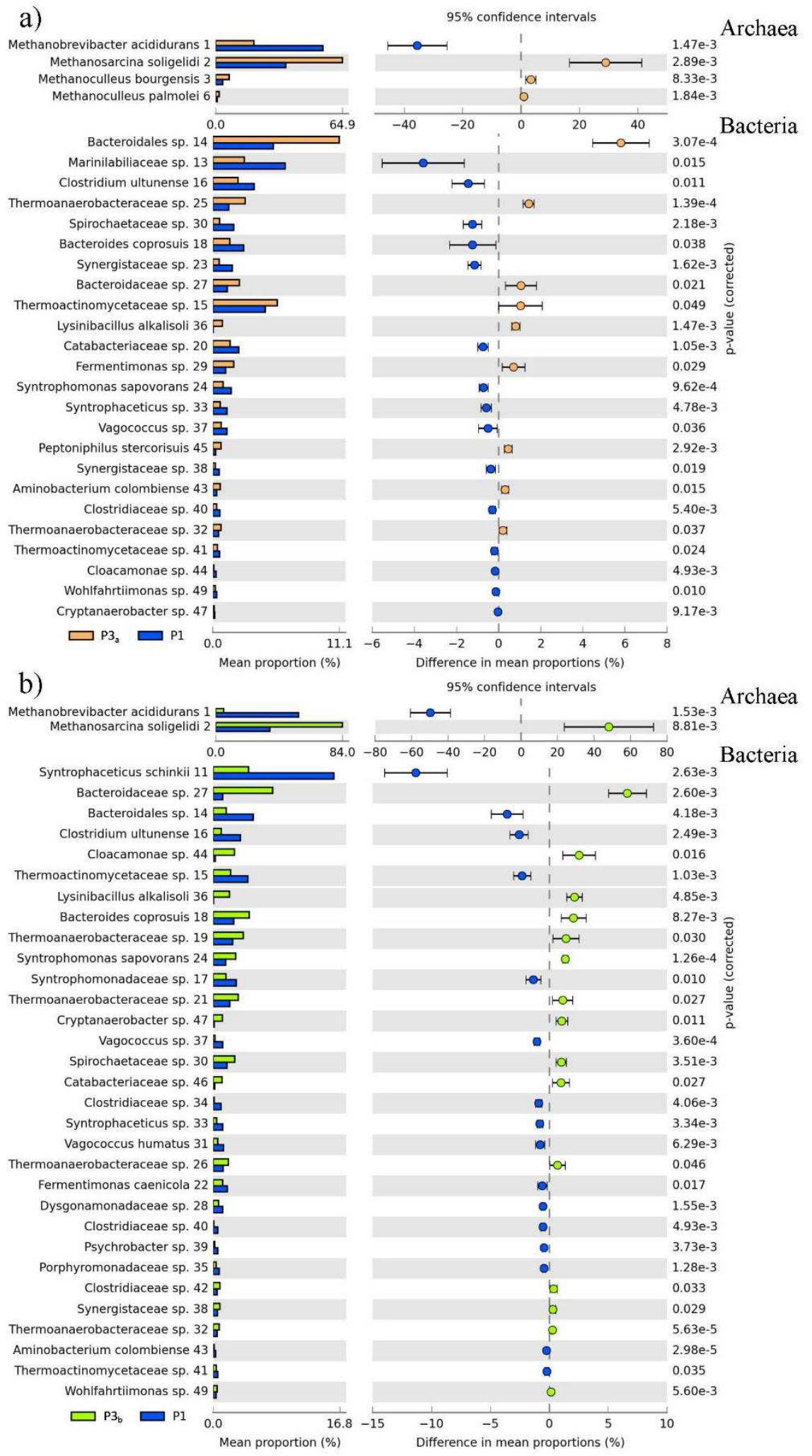

Fig. 5. OTUs that changed significantly $(p<0.05)$ among the most interesting OTUs a) 


\subsection{A proposed working mechanism for the bioaugmentation}

Overall, considering the improved reactor performance and changes of the microbial

359 composition, the success of the bioaugmentation in this study, i.e. the most possible

360 mechanism, lies on the "microbiological domino effect" triggered by the bioaugmented

361 M. bourgensis, which means that an efficient community could be established even with

362 the less dominant bioaugmentation culture (Fig. 6). Specifically, during the ammonia-

363 induced inhibited steady state, both bacteria and archaea were inhibited mainly by high

364 hydrogen partial pressure and synergistic inhibitory effect of ammonia and VFA.

365 However, the hydrogen partial pressure was reduced due to hydrogen consumption by

366 the bioaugmented hydrogenotrophic M. bourgensis, thus resulted in VFAs degradation

367 and synergistic inhibition mitigation. Therefore, overall favourable conditions were

368 created for the growth of ammonia-tolerant bacteria and archaea. For example,

369 propionate concentration decreased rapidly because of the increased abundance of

370 Bacteroidales sp. 14. Finally, as a result of the aforementioned "microbiological

371 domino effect", the whole microbial community was driven towards a more efficient

372 community degrading protein-rich substrate, evidenced by the increased relative

373 abundance of ammonia-tolerant methanogens, propionate degraders and fermentative

374 bacteria, etc. discussed above. 


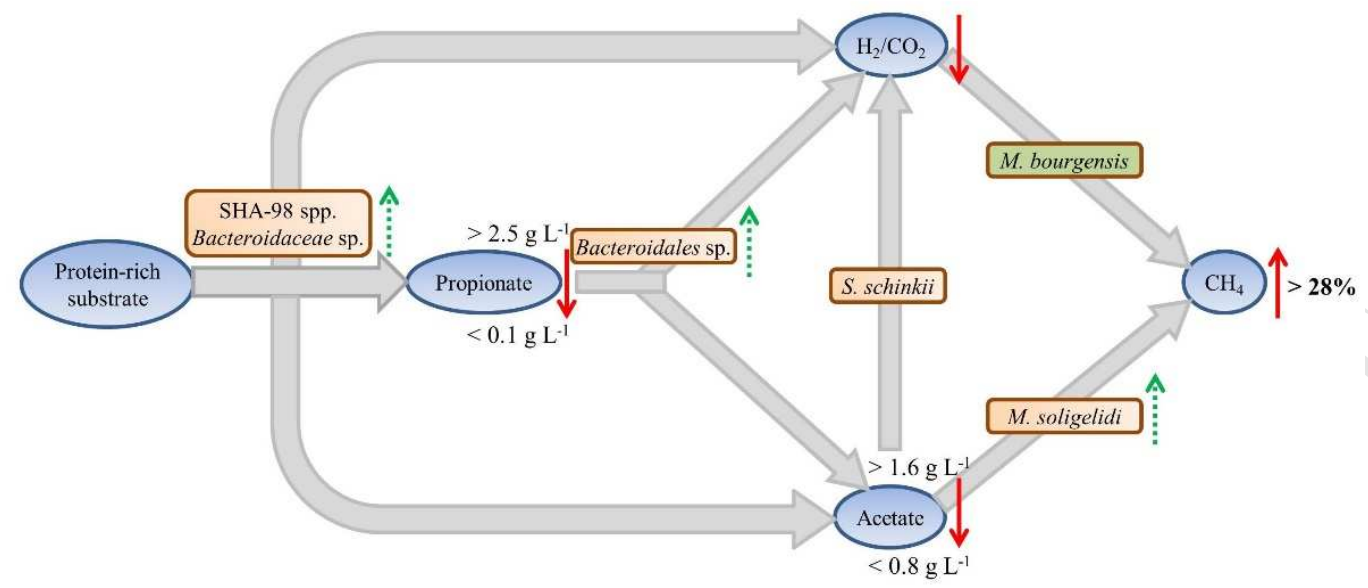

376 Fig. 6. A schematic diagram depicting the proposed working mechanism of the successful bioaugmentation. M. bourgensis was the bioaugmentation culture. Red solid and green dashed arrows present the change of the compound concentration and the OUT's relative abundance, respectively.

\section{Conclusions}

Bioaugmentation with pure hydrogenotrophic methanogen was proved, for the first

382 time, to alleviate ammonia inhibition of continuous $\mathrm{AD}$ reactor fed mainly with a

383 natural protein-rich biomass, namely microalgae, which are a $3^{\text {rd }}$ generation biomass,

384 under extremely high ammonia levels. Specifically, the bioaugmentation strategy

385 improved the methane yield by around $30 \%$ and decreased the VFA levels rapidly by 386 more than $80 \%$. Moreover, it seems that the removal of hydrogen and propionate played

387 an important role in alleviating inhibition and recovering methane production. The

388 microbial analysis demonstrated the significant community difference before and after

389 bioaugmentation, especially the increase in relative abundance of ammonia-tolerant

390 methanogens, propionate degraders (e.g. Bacteroidales sp. 14) and fermentative bacteria

391 (e.g. SHA-98). Furthermore, aceticlastic M. soligelidi was found to be the dominant 
392 methanogen at the end of the experiment. Finally, "microbiological domino effect"

393 triggered by the bioaugmented culture shaping a more efficient community was 394 proposed to be the main mechanism for the success of bioaugmentation.

\section{Acknowledgements}

This work was supported by Energinet.dk under the project framework ForskEL

"MicrobStopNH $\mathrm{N}_{3}$-Innovative bioaugmentation strategies to tackle ammonia inhibition in anaerobic digestion process" (program no. 2015-12327). Hailin Tian would like to thank for the financial support from China Scholarship Council (CSC). The authors thank Hector Garcia for his technical support during the experiments.

\section{Appendix A. Supplementary material}

Supplementary data of this article can be found in online version of the paper.

\section{References}

Albert, R.A., Waas, N.E., Pavlons, S.C., Pearson, J.L., Roecker, J., Tewalt, N., Cleeve, N., Rosselló-Mora, R., Busse, H.-J., 2016. Filimonas aurantiibacter sp. nov., an orange-pigmented bacterium isolated from lake water and emended description of the genus Filimonas. Int. J. Syst. Evol. Microbiol. 66, 4027-4032.

Alvarez, R., Lidén, G., 2008. Semi-continuous co-digestion of solid slaughterhouse waste, manure, and fruit and vegetable waste. Renew. Energy 33, 726-734.

Angelidaki, I., Ahring, B.K., 1994. Anaerobic thermophilic digestion of manure at different ammonia loads: Effect of temperature. Water Res. 28, 727-731.

412 APHA, 2012. Standard Methods for the Examination of Water and Wastewater. American Public Health Association, Washington, DC. 
414 Calli, B., Mertoglu, B., Inanc, B., Yenigun, O., 2005. Effects of high free ammonia

415 concentrations on the performances of anaerobic bioreactors. Process Biochem.

$416 \quad 40,1285-1292$.

417 Chen, C., Guo, W., Ngo, H.H., Lee, D.-J., Tung, K.-L., Jin, P., Wang, J., Wu, Y., 2016.

418 Challenges in biogas production from anaerobic membrane bioreactors. Renew.

$419 \quad$ Energy 98, 120-134.

420 Chen, Y., Cheng, J.J., Creamer, K.S., 2008. Inhibition of anaerobic digestion process: a review. Bioresour. Technol. 99, 4044-4064.

Chynoweth, D.P., Owens, J.M., Legrand, R., 2001. Renewable methane from anaerobic digestion of biomass. Renew. Energy 22, 1-8.

Dai, X., Hu, C., Zhang, D., Dai, L., Duan, N., 2017. Impact of a high ammonia425 ammonium-pH system on methane-producing archaea and sulfate-reducing bacteria in mesophilic anaerobic digestion. Bioresour. Technol. 245, 598-605.

DSMZ, 2014. 332. Methanogenium bourgense medium. Leibniz-Institut DSMZ Deutsche Sammlung von Mikroorganismen und Zellkulturen GmbH.

Fotidis, I.A., Treu, L., Angelidaki, I., 2017. Enriched ammonia-tolerant methanogenic cultures as bioaugmentation inocula in continuous biomethanation processes. $\mathrm{J}$. Cleaner Prod. 166, 1305-1313.

Fotidis, I.A., Wang, H., Fiedel, N.R., Luo, G., Karakashev, D.B., Angelidaki, I., 2014. Bioaugmentation as a solution to increase methane production from an ammoniarich substrate. Environ. Sci. Technol. 48, 7669-7676.

435 Gao, S., Zhao, M., Chen, Y., Yu, M., Ruan, W., 2015. Tolerance response to in situ 436 ammonia stress in a pilot-scale anaerobic digestion reactor for alleviating ammonia inhibition. Bioresour. Technol. 198, 372-379. 
438 Hansen, K.H., Angelidaki, I., Ahring, B.K., 1998. Anaerobic digestion of swine manure: 439 inhibition by ammonia. Water Res. 32, 5-12.

440 Hao, L., Lü, F., Mazéas, L., Desmond-Le Quéméner, E., Madigou, C., Guenne, A.,

441

442

443

444

445

446

447

448

449

450

451

452

453

454

455

456

457

458

459
Shao, L., Bouchez, T., He, P., 2015. Stable isotope probing of acetate fed anaerobic batch incubations shows a partial resistance of acetoclastic methanogenesis catalyzed by Methanosarcina to sudden increase of ammonia level. Water Res. 69, 90-99.

Hao, X., Liu, R., van Loosdrecht, M.C.M., Cao, D., 2017. Batch influences of exogenous hydrogen on both acidogenesis and methanogenesis of excess sludge. Chem. Eng. J. 317, 544-550.

Holliger, C., Alves, M., Andrade, D., Angelidaki, I., Astals, S., Baier, U., Bougrier, C., Buffiere, P., Carballa, M., de Wilde, V., Ebertseder, F., Fernandez, B., Ficara, E., Fotidis, I., Frigon, J.C., de Laclos, H.F., Ghasimi, D.S., Hack, G., Hartel, M., Heerenklage, J., Horvath, I.S., Jenicek, P., Koch, K., Krautwald, J., Lizasoain, J., Liu, J., Mosberger, L., Nistor, M., Oechsner, H., Oliveira, J.V., Paterson, M., Pauss, A., Pommier, S., Porqueddu, I., Raposo, F., Ribeiro, T., Rusch Pfund, F., Stromberg, S., Torrijos, M., van Eekert, M., van Lier, J., Wedwitschka, H., Wierinck, I., 2016. Towards a standardization of biomethane potential tests. Water Sci. Technol. 74, 2515-2522.

Kim, S.-J., Park, J.-H., Lim, J.-M., Ahn, J.-H., Anandham, R., Weon, H.-Y., Kwon, S.W., 2014. Parafilimonas terrae gen. nov., sp. nov., isolated from greenhouse soil. Int. J. Syst. Evol. Microbiol. 64, 3040-3045. 
460 Kougias, P.G., Fotidis, I.A., Zaganas, I.D., Kotsopoulos, T.A., Martzopoulos, G.G., 461 2013. Zeolite and swine inoculum effect on poultry manure biomethanation. Int. $462 \quad$ Agrophys. 27.

463 Kovacs, E., Wirth, R., Maroti, G., Bagi, Z., Nagy, K., Minarovits, J., Rakhely, G., 464 Kovacs, K.L., 2015. Augmented biogas production from protein-rich substrates and associated metagenomic changes. Bioresour. Technol. 178, 254-261.

Lay, J.J., Li, Y.Y., Noike, T., 1998. The influence of $\mathrm{pH}$ and ammonia concentration on the methane production in high-solids digestion processes. Water Environ. Res 70, 1075-1082.

Lu, F., Hao, L., Guan, D., Qi, Y., Shao, L., He, P., 2013. Synergetic stress of acids and ammonium on the shift in the methanogenic pathways during thermophilic anaerobic digestion of organics. Water Res. 47, 2297-2306.

Luo, G., De Francisci, D., Kougias, P.G., Laura, T., Zhu, X., Angelidaki, I., 2015. New steady-state microbial community compositions and process performances in biogas reactors induced by temperature disturbances. Biotechnol. Biofuels 8,3 .

Mahdy, A., Fotidis, I.A., Mancini, E., Ballesteros, M., Gonzalez-Fernandez, C., Angelidaki, I., 2017. Ammonia tolerant inocula provide a good base for anaerobic digestion of microalgae in third generation biogas process. Bioresour. Technol. $225,272-278$.

Massé, D.I., Droste, R.L., 2000. Comprehensive model of anaerobic digestion of swine manure slurry in a sequencing batch reactor. Water Res. 34, 3087-3106.

Massé, D.I., Rajagopal, R., Singh, G., 2014. Technical and operational feasibility of 482 psychrophilic anaerobic digestion biotechnology for processing ammonia-rich waste. Appl. Energy 120, 49-55. 
484 Mei, R., Narihiro, T., Nobu, M.K., Kuroda, K., Liu, W.-T., 2016. Evaluating digestion 485 efficiency in full-scale anaerobic digesters by identifying active microbial 486 populations through the lens of microbial activity. Sci. Rep. 6, 34090.

487 Müller, B., Sun, L., Westerholm, M., Schnürer, A., 2016. Bacterial community 488 composition and fhs profiles of low- and high-ammonia biogas digesters reveal 489 novel syntrophic acetate-oxidising bacteria. Biotechnol Biofuels 9, 48.

490 Nielsen, H.B., Angelidaki, I., 2008. Strategies for optimizing recovery of the biogas 491 process following ammonia inhibition. Bioresour. Technol. 99, 7995-8001.

492 Parks, D.H., Beiko, R.G., 2010. Identifying biologically relevant differences between metagenomic communities. Bioinformatics 26, 715-721.

494 Saeed, A.I., Bhagabati, N.K., Braisted, J.C., Liang, W., Sharov, V., Howe, E.A., Li, J., 495 Thiagarajan, M., White, J.A., Quackenbush, J., 2006. [9] TM4 Microarray 496 Software Suite. Methods Enzymol. Academic Press, pp. 134-193.

497 Savant, D.V., Shouche, Y.S., Prakash, S., Ranade, D.R., 2002. Methanobrevibacter 498 acididurans sp. nov., a novel methanogen from a sour anaerobic digester. Int. J. Syst. Evol. Microbiol. 52, 1081-1087.

500 Schnürer, A., Bernhard Schink, and Bo H. Svensson, 1996. Clostridium ultunense sp. nov., a mesophilic bacterium oxidizing acetate in syntrophic association with a hydrogenotrophic methanogenic bacterium. Int. J. Syst. Evol. Microbiol. 46,

504 Tale, V.P., Maki, J.S., Zitomer, D.H., 2015. Bioaugmentation of overloaded anaerobic digesters restores function and archaeal community. Water Res. 70, 138-147. 
506 Tian, H., Fotidis, I.A., Mancini, E., Angelidaki, I., 2017. Different cultivation methods to acclimatise ammonia-tolerant methanogenic consortia. Bioresour. Technol. 232, $1-9$.

Tian, H., Fotidis, I.A., Mancini, E., Treu, L., Mahdy, A., Ballesteros, M., GonzálezFernández, C., Angelidaki, I., 2018a. Acclimation to extremely high ammonia levels in continuous biomethanation process and the associated microbial community dynamics. Bioresour. Technol. 247, 616-623.

Tian, H., Karachalios, P., Angelidaki, I., Fotidis, I.A., 2018b. A proposed mechanism for the ammonia-LCFA synergetic co-inhibition effect on anaerobic digestion process. Chem. Eng. J. 349, 574-580.

Treu, L., Campanaro, S., Kougias, P.G., Sartori, C., Bassani, I., Angelidaki, I., 2018. Hydrogen-Fueled Microbial Pathways in Biogas Upgrading Systems Revealed by Genome-Centric Metagenomics. Front. Microbiol. 9.

Tsapekos, P., Kougias, P.G., Vasileiou, S.A., Treu, L., Campanaro, S., Lyberatos, G., Angelidaki, I., 2017. Bioaugmentation with hydrolytic microbes to improve the anaerobic biodegradability of lignocellulosic agricultural residues. Bioresour. Technol. 234, 350-359.

Van Lier, J.B., Grolle, K.C., Frijters, C.T., Stams, A.J., Lettinga, G., 1993. Effects of acetate, propionate, and butyrate on the thermophilic anaerobic degradation of propionate by methanogenic sludge and defined cultures. Appl. Environ. Microbiol. 59, 1003-1011.

Wang, Y., Zhang, Y., Wang, J., Meng, L., 2009. Effects of volatile fatty acid concentrations on methane yield and methanogenic bacteria. Biomass Bioenergy $33,848-853$. 
530 Werner, J.J., Garcia, M.L., Perkins, S.D., Yarasheski, K.E., Smith, S.R., Muegge, B.D., 531 Stadermann, F.J., DeRito, C.M., Floss, C., Madsen, E.L., 2014. Microbial 532 community dynamics and stability during an ammonia-induced shift to syntrophic 533 acetate oxidation. Appl. Environ. Microbiol. 80, 3375-3383.

534 Westerholm, M., Roos, S., Schnürer, A., 2010. Syntrophaceticus schinkii gen. nov., sp. 535 nov., an anaerobic, syntrophic acetate-oxidizing bacterium isolated from a 536 mesophilic anaerobic filter. FEMS Microbiol. Lett. 309, 100-104.

537 Yang, Z., Wang, W., He, Y., Zhang, R., Liu, G., 2018. Effect of ammonia on methane 538 production, methanogenesis pathway, microbial community and reactor 539 performance under mesophilic and thermophilic conditions. Renew. Energy 125, $540 \quad 915-925$.

541 Yenigün, O., Demirel, B., 2013. Ammonia inhibition in anaerobic digestion: A review. Process Biochem. 48, 901-911.

543 Yuan, M.-H., Chen, Y.-H., Tsai, J.-Y., Chang, C.-Y., 2016. Ammonia removal from 544 ammonia-rich wastewater by air stripping using a rotating packed bed. Process $545 \quad$ Saf. Environ. Prot. 102, 777-785.

546 Zinder, S.H., Koch, M., 1984. Non-aceticlastic methanogenesis from acetate: acetate oxidation by a thermophilic syntrophic coculture. Arch. Microbiol. 138, 263-272. 


\section{Highlights}

- Bioaugmentation alleviated ammonia inhibition of a reactor fed with microalgae

- Bioaugmented M. bourgensis increased methane yield by $28 \%$ and decreased VFA by $80 \%$

- Reduction of hydrogen pressure and propionate is crucial in alleviating inhibition

- The bioaugmentation success lies on the triggered "microbiological domino effect"

- M. soligelidi was the dominant methanogen three HRTs after bioaugmentation 